\title{
Bacterial adhesion to oropharyngeal and bronchial epithelial cells in smokers with chronic bronchitis and in healthy nonsmokers
}

\author{
G.C. Riise*, S. Larsson*, B.A. Andersson**
}

Bacterial adhesion to oropharyngeal and bronchial epithelial cells in smokers with chronic bronchitis and in healthy nonsmokers. G.C. Riise, S. Larsson, B.A. Andersson. (CERS Journals Ltd 1994.

ABSTRACT: Bacterial adhesion is probably a prerequisite for colonization of mucous membranes, but adhesion to the bronchial mucosa has not been studied in detail. We investigated adhesion of respiratory pathogens to bronchial epithelial cells, and asked whether chronic bronchitis had an influence on bacterial adhesion.

Oropharyngeal and bronchial cells were collected during bronchoscopy from 14 healthy nonsmokers, 22 smokers with nonobstructive chronic bronchitis, and 19 smokers with chronic bronchitis and chronic obstructive pulmonary disease (COPD). Patients with a forced expiratory volume in one second $\left(F_{E V}\right)$ less than $50 \%$ predicted were excluded. Adhesion of highly adherent test strains of $\mathrm{H}$. influenzae and $S$. pneumoniae to these cells were studied.

The test strains of $H$. influenzae and $S$. pneumoniae were found to adhere well to both oropharyngeal and bronchial cells. $H$. influenzae showed a higher degree of adhesion both to ciliated and goblet cells from the patients with nonobstructive bronchitis than to cells from the healthy nonsmokers. No corresponding difference was found for $S$. pneumoniae. The patients with COPD did not differ from the controls in their adhesion values.

Our results indicate that bacterial adhesion is of importance for the colonization and retention of $H$. influenzae in the human airways. For $S$. pneumoniae the role of adhesion is more uncertain.

Eur Respir J., 1994, 7, 1759-1764.
Depts of *Pulmonary Medicine, Renström's Hospital, and **Clinical Immunology, Göteborg University, Gothenburg, Sweden.

Correspondence: G.C. Riise Dept of Pulmonary Medicine

Renström's Hospital

P.O.B. 17301

S-402 64 Gothenburg

Sweden

Keywords: Bacterial adhesion chronic bronchitis

Received: January 121994

Accepted after revision May 271994

This study was supported by grants from The Swedish Heart and Lung Foundation, the Swedish Society for Medicine, and the Medical Society of Göteborg.
Bacterial adhesion may be an important factor favouring bacterial persistence and colonization of the respiratory tract [1-3]. Most studies have investigated bacterial adhesion of Streptococcus pneumoniae and Haemophilus influenzae to oropharyngeal and buccal cells, either to exfoliated cells or to nasopharyngeal mucosal biopsies. Adhesion has also been demonstrated to exfoliated human bronchial cells for the airway pathogens Bordetella pertussis [4], Pseudomonas aeruginosa [5], and Staphylococcus aureus [6].

Smokers have been shown to have an enhanced adherence of $S$. pneumoniae to buccal cells [7, 8], and smokers with chronic bronchitis appear to have increased adherence of $H$. influenzae to their pharyngeal cells [9]. However, the effect of the smoke-induced airway disease, chronic bronchitis, on bacterial adhesion to bronchial epithelial cells is not known.

Chronic bronchitis is characterized by bronchial hypersecretion and productive cough. Some patients with chronic bronchitis are prone to recurrent infectious exacerbations with sputum purulence, and some develop airway obstruction as part of the disease entity, chronic obstructive pulmonary disease (COPD) [10]. Patients with chronic bronchitis have a higher frequency of positive bacterial cultures from the lower respiratory tract than healthy individuals $[11,12]$. Studies in chronic bronchitis have shown that, both at acute infectious exacerbations and at intervals free from exacerbations, about half of the patients are colonized intrabronchially with bacteria belonging to the nasopharyngeal flora $[13,14]$. The species cultured include $\alpha$-haemolytic streptococci, S. pneumoniae, $H$. influenzae and coagulase negative staphylococci $[15,16]$. Why only some, and not all, patients with chronic bronchitis develop exacerbations is not known.

The first object of the present investigation was to study adhesion of $S$. pneumoniae and $H$. influenzae to human respiratory cells. Secondly, to determine whether the smoke-induced airway diseases, chronic bronchitis and COPD, change the ability of bronchial cells to adhere $S$. pneumoniae and $H$. influenzae. Thirdly, to investigate whether changed adhesion could be a factor promoting recurrent infectious exacerbations in chronic bronchitis.

\section{Material and methods}

\section{Design}

Bacterial adhesion of test strains of S. pneumoniae and $H$. influenzae to epithelial cells from the upper and 
lower respiratory tract was evaluated. Adhesion to cells sampled from 41 patients with chronic bronchitis were compared to cells taken from 14 healthy nonsmoking controls.

\section{Subjects}

The control group comprised 14 healthy nonsmoking volunteers with normal spirometry and no signs of infectious respiratory disease during the previous 4 weeks. The patient group comprised 41 patients with chronic bronchitis. All were current smokers with productive daily cough for at least three consecutive months each year during the past 2 yrs. They were subdivided into four groups, according to presence or absence of airway obstruction, and presence or absence of recurrent infectious exacerbations:

1. Twelve patients with nonobstructive chronic bronchitis with less than two recurrent infectious exacerbations in the past 2 years, as defined by Boman et al. [17]. They had normal spirometry (defined as a forced expiratory volume in one second $\left(\mathrm{FEV}_{1}\right)>80 \%$ of predicted and no reversibility on $\beta_{2}$-agonists).

2. Ten patients with nonobstructive chronic bronchitis with at least three or more infectious exacerbations in the past two yrs.

3. Eleven patients with chronic bronchitis and COPD (defined as a $\mathrm{FEV}_{1}<80 \%$ of predicted and no reversibility on $\beta_{2}$-agonists) and with less than two exacerbations in the past 2 yrs.

4. Eight patients with chronic bronchitis and COPD with at least three or more infectious exacerbations in the past 2 yrs.

Eight nonobstructive chronic bronchitis patients used $\beta_{2}$-agonists for inhalation at irregular intervals. Of the patients with chronic bronchitis and COPD, eight used oral $\mathrm{N}$-acetylcysteine (NAC) regularly $(200 \mathrm{mg}$ at least twice daily), eight used $\beta_{2}$-agonists for inhalation at irregular intervals, and four used inhaled steroids regularly. None used theophylline preparations or oral steroids. The duration of the bronchitis symptoms in the patient group varied from 2.5 to 24 yrs, with a mean of 12.5 yrs.

Criteria for exclusion were abnormal chest X-ray, bronchial hypersecretion caused by factors other than cigarette smoking, a history of asthma or reversibility $>10 \%$ on $\beta_{2}$-agonists, and for safety reasons a FEV less than $50 \%$ predicted or age more than 70 yrs. Ventilatory lung function $\left(\mathrm{FEV}_{1}\right)$ was measured with a Bernstein spirometer or Vitalograph.
The mean age and the mean maximum $\mathrm{FEV}_{1}$ (in percentage of predicted normal) did not differ substantially between the healthy controls and the patients with nonobstructive chronic bronchitis. The patients with chronic bronchitis and COPD were significantly older than the healthy controls, and had a lower FEV than the controls and the patients with nonobstructive chronic bronchitis. The smoking history of the four subgroups with chronic bronchitis was comparable (table 1).

The study design was approved by the local Ethics Committee and the volunteers gave their consent after written and oral information.

\section{Bronchoscopy}

Premedication was given with haloperidol, $5 \mathrm{mg}$ orally followed by $0.5-1 \mathrm{ml}$ morphine-scopolamine i.m. Five millilitres $1 \%$ tetracaine, without preservative, was nebulized with a pressurized nebulizer (Plug-in inhalator, Aiolos systems, Karlstad, Sweden) and inhaled in an upright position for local anaesthesia. All bronchoscopies were performed transorally by one of two experienced bronchoscopists, and with the patient in the supine position. Olympus flexible fibreoptic bronchoscopes of several models were used.

\section{Collection of samples}

Epithelial cells were scraped from the oropharynx with a cotton-tipped wooden swab and suspended in phosphate-buffered saline.

Bronchial brush biopsies for adhesion studies were taken during bronchoscopy using a standard cytology brush (Olympus BC 9C-26101). Three consecutive brushings from an approximately $2-4 \mathrm{~cm}^{2}$ intrabronchial area were sampled from two levels in the bronchial tree: from the carina level and from the subsegmental bronchial level in the right lower lobe. Two separate brushes were used for the two levels. The samples were immediately fixed in buffered $5 \%$ formaldehyde. A pilot study using airway cells taken from patients, mostly smokers, undergoing routine bronchoscopy for investigation of various airway diseases had previously shown that formaldehyde fixation caused no interfeence with bacterial adhesion (data not shown). The cells were stained with a drop of Sedistain (Clay Adams, Becton Dickinson, Parsippany, NJ 07054, USA) and

Table 1. - Age, $\mathrm{FEV}_{1}$ and cigarette consumption of healthy controls, patients with chronic bronchitis, and patients with chronic bronchitis and COPD

\begin{tabular}{|c|c|c|c|c|c|c|c|}
\hline \multirow[b]{2}{*}{ Healthy controls } & \multicolumn{3}{|c|}{ Age* } & \multicolumn{2}{|c|}{$\begin{array}{l}\mathrm{FEV}_{1} * * \\
\% \text { pred }\end{array}$} & Pack-years** & \\
\hline & 14 & 46 & $(26-66)$ & 101 & (1) & 0 & \\
\hline Chronic bronchitis without infectious exacerbations & 12 & 49 & $(36-62)$ & 96 & (2) & 35 & (2) \\
\hline Chronic bronchitis with infectious exacerbations & 10 & 55 & $(48-68)$ & 87 & (2) & 36 & $(2)$ \\
\hline Bronchitis and COPD without infectious exacerbations & 11 & 60 & $(44-70)$ & 63 & (3) & 43 & (2) \\
\hline Bronchitis and COPD with infectious exacerbations & 8 & 54 & $(38-66)$ & 63 & (3) & 45 & (2) \\
\hline
\end{tabular}

*: data are presented as mean and range in parenthesis; $* *$ : data are presented as mean and SEM in parenthesis. FEV $\mathrm{F}_{1}$ forced expiratory volume in one second; COPD: chronic obstructive pulmonary disease; \% pred: percentage of predicted normal. 
morphologically analysed using an interference contrast microscope (Optophot II, Nikon, Fuji Bldg, 2-3, Marunouchi 3-chome, Chiyoda-ku, Tokyo 100, Japan).

\section{Bacteria}

The ability of epithelial cells sampled from the oropharynx and the bronchi of patients with chronic bronchitis and healthy controls to bind bacteria was analysed by using two highly adherent bacterial test strains: nontypable $H$. influenzae CCUG (culture collection of the University of Göteborg) 21594 isolated from the nasopharynx of a child with acute otits media, and S. pneumoniae CCUG 10175, type 19F, isolated from the nasopharynx of a healthy child. All bacteria were kept lyophilized until used for the adhesion analysis.

\section{Adhesion assay}

Bacteria were cultivated on solid medium over night, and then in liquid medium for $10 \mathrm{~h}$ as described previously $[18,19]$. After washing, $10^{4}$ cells $\cdot \mathrm{ml}^{-1}$ were mixed with $10^{9}$ bacteria $\cdot \mathrm{ml}^{-1}$ in a total volume of $200 \mu 1$. The mixture was centrifuged at $1,500 \times \mathrm{G}$ for $10 \mathrm{~min}$ and incubated at $37^{\circ} \mathrm{C}$ for $30 \mathrm{~min}$. Unattached bacteria were separated from the epithelial cells by two cycles of suspension in a buffer of physiological saline $(0.9 \%)$ with $10 \mathrm{mg} \cdot \mathrm{ml}^{-1}$ choline chloride and centrifugation at $500 \times$ $\mathrm{G}$ for $10 \mathrm{~min}$. The mean number of adhering bacteria per epithelial cell was counted using an interference contrast microscope. The analysis was performed without any knowledge of which subject group the cells had been taken from. In the bronchial brush biopsy samples, each cell type with at least 20 analysable cells was included. In samples containing a high number of cells, 40 cells were analysed.

For oropharyngeal cells, adhesion was arbitrarily defined as high at $\geq 40$ bacteria.cell $^{-1}$, intermediate at 10-40 bacteria.cell ${ }^{-1}$ and low at $<10$ bacteria $\cdot$ cell $^{-1}$. For the smaller bronchial epithelial cells, high adhesion was arbitrarily defined as $>10$ bacteria.cell ${ }^{-1}$.

For technical reasons, it cannot be excluded that some of the cells classified as goblet cells covered with bacteria were damaged columnar epithelial cells with oedema and without cilia. Similar methodological difficulties have been described previously by other investigators [20].

To estimate the natural variation in bacterial adhesion over time for the two test strains, we used cells from a nonsmoking healthy individual (BA) as a reference for each adhesion experiment. The mean adhesion values for the $H$. influenzae test strain to the BA cells did not differ statistically when used for the study of healthy subjects 32 (SD 14), chronic bronchitis patients 27 (SD 18 ) and COPD patients 29 (SD 18). Nor did the mean adhesion values for the $S$. pneumoniae test strain to the oropharyngeal cells of BA differ statistically when used parallel to the study of healthy subjects 110 (SD 49), chronic bronchitis 90 (SD 30) and COPD 84 (SD 42).

\section{Statistical analysis}

The bacterial adhesion values were calculated using the arithmetic mean and standard deviation. The Student's t-test was used for the comparison of the distribution of the bacterial adhesion values between groups of subjects. Multiple regression analysis was used to determine whether patient factors such as age, smoking habits, duration of bronchitis symptoms, FEV 1 values or serum levels of immunoglobulin (Ig) A, M, G and IgG-subclasses had an influence on the bacterial adhesion.

\section{Results}

\section{Adhesion of bacterial test strains to oropharyngeal epithe- lial cells}

A pronounced adhesion of $H$. influenzae CCUG 21594 and S. pneumoniae CCUG 10175 to the oropharyngeal epithelial cells both from patients and controls is shown in table 2 . No statistically significant

Table 2. - Adhesion of H. influenzae (CCUG 21594) and S. pneumoniae (CCUG 10175) to oropharyngeal epithelial cells from healthy controls, patients with chronic bronchitis, and patients with chronic bronchitis and COPD, and with and without exacerbations, respectively

\begin{tabular}{|c|c|c|c|c|c|c|c|}
\hline \multirow{4}{*}{$\begin{array}{l}\text { Subject category } \\
\text { Healthy controls }\end{array}$} & \multicolumn{7}{|c|}{ Adhesion } \\
\hline & \multicolumn{3}{|c|}{ H. influenzae } & \multirow{3}{*}{$\mathrm{p}$} & \multicolumn{3}{|c|}{ S. pneumoniae } \\
\hline & \multirow{2}{*}{$\frac{n}{14}$} & \multicolumn{2}{|c|}{ bacteria $\cdot$ cell $^{-1}$} & & \multicolumn{2}{|c|}{ bacteria $\cdot$ cell $^{-1}$} & \multirow[t]{2}{*}{$\mathrm{p}$} \\
\hline & & 55 & $(38)$ & & 149 & (67) & \\
\hline Chronic bronchitis, total group & 22 & 55 & (26) & NS & 184 & (78) & NS \\
\hline Without exacerbations & 12 & 61 & (23) & NS & 176 & (70) & NS \\
\hline With exacerbations & 10 & 47 & $(28)$ & NS & 194 & $(88)$ & NS \\
\hline Chronic bronchitis and COPD, total group & 19 & 66 & (50) & NS & 135 & (67) & NS \\
\hline Without exacerbations & 11 & 66 & (50) & NS & 147 & (67) & NS \\
\hline With exacerbations & 8 & 61 & (34) & NS & 116 & (68) & NS \\
\hline
\end{tabular}

Data are presented as mean and SD in parenthesis. CCUG: culture collection of the University of Göteborg; COPD: chronic obstructive pulmonary disease; Ns: nonsignificant. 


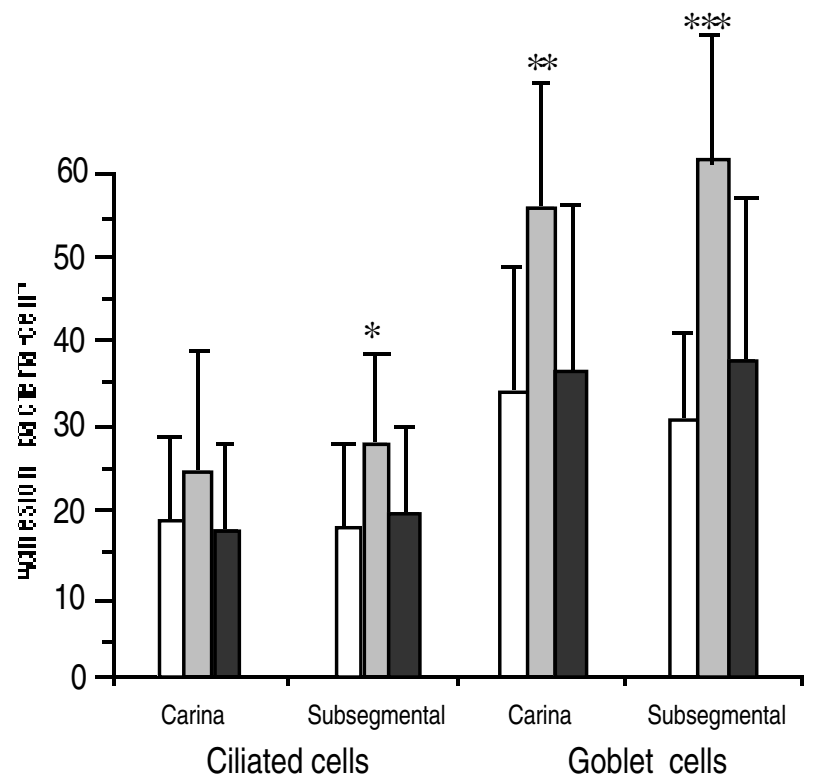

Fig. 1. - Adhesion of H. influenzae (CCUG 21594) to bronchial epithelial cells from the carina and subsegmental levels in healthy nonsmoking controls $(n=13)$, smokers with nonobstructive chronic bronchitis $(n=19)$, and smokers with chronic bronchitis and COPD $(n=18)$. Data are presented as mean and SD. Significantly higher adhesion compared to corresponding cells from healthy controls. *: $\mathrm{p}<0.05$; **: $\mathrm{p}<0.01$; ***:p $<0.001 . \square$ : healthy controls; $\square$ : nonobstructive chronic bronchitis; $\square$ : chronic bronchitis and COPD. COPD: chronic obstructive pulmonary disease.

difference was found between cells from bronchitic patients and controls, nor between nonobstructive chronic bronchitis patients and patients with chronic bronchitis and COPD.

\section{Adhesion of bacterial test strains to bronchial epithelial cells}

There was a significantly higher adhesion of H. influenzae CCUG 21594 to ciliated columnar epithelial cells from the subsegmental level of patients with nonobstructive chronic bronchitis compared to the corresponding cells from healthy controls $(\mathrm{p}<0.05)$. Furthermore, there was a significantly higher adhesion to goblet cells both from the carina level $(\mathrm{p}<0.001)$ and the subsegmental level $(\mathrm{p}<0.01)$. The patients with chronic bronchitis and COPD had no significant differences

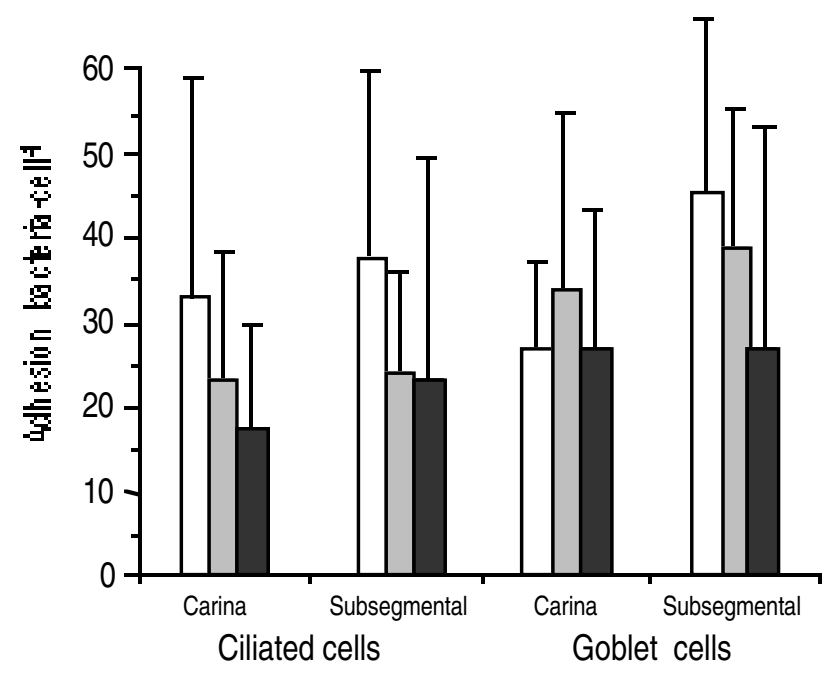

Fig 2. - Adhesion of S. pneumoniae (CCUG 10175) to bronchial epithelial cells from the carina and subsegmental levels in healthy nonsmoking controls $(n=13)$, smokers with nonobstructive chronic bronchitis $(n=19)$, and smokers with chronic bronchitis and COPD $(n=18)$. Data are presented as mean and SD. $\square$ : healthy controls; $\square$ : nonobstructive chronic bronchitis; $\square$ : chronic bronchitis and COPD.

in adherence of $H$. influenzae CCUG 21594 to any bronchial cell type compared to the controls (fig. 1).

There was a high bacterial binding of S. pneumoniae CCUG 10175 to bronchial epithelial cells both from patients and controls. No statistically significant difference was found between cells from bronchitis patients and controls, or between cells from the nonobstructive chronic bronchitis patients and the patients with chronic bronchitis and COPD (fig. 2).

No significant difference in adhesion could be demonstrated for $H$. influenzae CCUG 21594 or S. pneumoniae CCUG 10175 to bronchial epithelial cells from patients with and without infectious exacerbations (table 3 ). Nor was any difference seen in adhesion between cells from the upper and lower sampling levels in the bronchial tree.

Multiple regression analysis was used to determine whether patient factors such as age, smoking habits, duration of bronchitis symptoms, $\mathrm{FEV}_{1}$ values, and serum levels of immunoglobulin A, M, G and IgG subclasses had an influence on the bacterial adhesion. No significant covariation was found (data not shown).

Table 3. - Adhesion of $\mathrm{H}$. influenzae (CCUG 21594) to ciliated epithelial cells and goblet cells from all patients with chronic bronchitis, with and without infectious exacerbations

\begin{tabular}{|c|c|c|c|c|c|c|c|}
\hline \multirow[b]{3}{*}{ Cell type } & \multicolumn{7}{|c|}{ Adhesion } \\
\hline & \multicolumn{3}{|c|}{ With exacerbations } & \multicolumn{4}{|c|}{ Without exacerbations } \\
\hline & \multicolumn{2}{|c|}{ bacteria $\cdot$ cell $^{-1}$} & \multirow[t]{2}{*}{$\mathrm{n}$} & \multicolumn{2}{|c|}{ bacteria $\cdot$ cell $^{-1}$} & \multirow[t]{2}{*}{$\mathrm{n}$} & \multirow[t]{2}{*}{$\mathrm{p}$} \\
\hline Cmatea epitnan cens & & & & & & & \\
\hline Carina level & 23 & (12) & 17 & 27 & (19) & 23 & NS \\
\hline Subsegmental level & 25 & (15) & 17 & 29 & (17) & 22 & NS \\
\hline \multicolumn{8}{|l|}{ Goblet cells } \\
\hline Carina levels & 21 & (27) & 13 & 22 & (26) & 18 & NS \\
\hline Subsegmental level & 22 & (29) & 12 & 21 & (29) & 15 & NS \\
\hline
\end{tabular}

Data are presented as mean and SD in parenthesis. For abbreviations see legend to table 2. 
The differing subject numbers for bacterial adhesion to bronchial cells in figures 1 , and 2 and table 3 are due to exclusion of subjects with too few analysable cells.

\section{Discussion}

For $H$. influenzae, the following picture of bacterial adhesion emerges. Both oropharyngeal and bronchial epithelial cells showed a high binding capacity for the $H$. influenzae test strain in the present study. We also found that two strains of $H$. influenzae isolated from the bronchi of the patients in the present study adhered well to oropharyngeal and bronchial epithelial cells (unpublished data). In chronic bronchitis, the ability of epithelial cells from the respiratory tract to bind $H$. influenzae seems to be increased. FAINSTAIN and MUSHER [9] have previously demonstrated a higher adhesion of $H$. influenzae to oropharyngeal epithelial cells from patients with chronic bronchitis than to cells from healthy controls [9]. This could not be confirmed in our study. However, a significantly higher binding of $H$. influenzae was found to bronchial goblet and ciliated cells from patients with nonobstructive chronic bronchitis as compared to cells from the healthy controls. These results are consistent with the idea that adherence of $H$. influenzae is possibly an important factor in the colonization of the airways, and may help provide an explanation for the reported tendency for patients with chronic bronchitis to retain $H$. influenzae on their bronchial epithelial surfaces [21].

For $S$. pneumoniae the situation is more complex. The pneumococcal test strain, used in the present study, with a known high adhesive capacity, adhered well to both the oropharyngeal and bronchial epithelial cells. We have previously demonstrated that a high frequency of pneumococcal strains adhering well to oropharyngeal cells can be found in isolates from the middle ear, in acute otitis media (AOM), and from the nasopharyngeal mucosa $[18,22]$. However, approximately $45 \%$ of the isolates from these sites proved to be poorly adherent to oropharyngeal cells $[18,22]$. We have also found that strains demonstrating poor adherence are over-represented among certain common serotypes. In 20 blood isolates of pneumococcus type 3 from adults with septicaemia, we found a mean adhesion of only 2 bacteria.cell ${ }^{-1}$ (99\% confidence interval

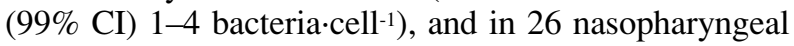
isolates of pneumococcus type 3 from children with AOM a mean adhesion of 3 bacteria $\cdot$ cell $^{-1}$ (99\% CI 0-

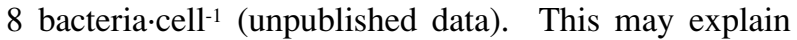
why earlier studies using pneumococcal strains of capsular type 3 were unable to show adhesion [23-25]. The data from the present study demonstrate that strains adhering to epithelial cells from both the upper and the lower airways exist. It is, however, unclear if bacterial adhesion to bronchial epithelial cells is of importance for the colonization of pneumococci.

Smoking has been found to increase the tendency of oropharyngeal cells to bind $S$. pneumoniae [7, 8]. A similar, although not statistically significant, trend was seen for the test strain in our study. However, no increased adhesion of S. pneumoniae was seen to bronchial cells from the patients with chronic bronchitis as compared to cells from the controls.

No statistically significant difference in bacterial binding could be demonstrated for either test strain to cells from the patients with chronic bronchitis and COPD as compared to the controls. This is surprising, as a convincing difference was found between the nonobstructive patients and the controls for $H$. influenzae. Furthermore, as we reported previously [12], the patients with COPD showed an intrabronchial bacterial flora comparable to that of the nonobstructive patients. As the cells from the COPD patients were collected somewhat later in time, we investigated whether the adhesive properties of the test strains had changed, but no evidence for this could be found. There was, however, a greater range of the adhesion data for the COPD patients than for the other groups, and in some COPD patients a very high bacterial adhesion to the bronchial epithelial cells was demonstrated.

No differences in adhesive properties were found for cells taken from patients with and without recurrent infectious exacerbations. We chose to use highly adherent test strains in the present study to optimize the conditions for a possible demonstration of bacterial adhesion to bronchial cells. However, it is possible that such test strains could also cause saturation of adhering bacteria to cells which have a low tendency for bacterial adhesion. Thus, subtle differences between subject groups, such as the patients with and without infectious exacerbations, could have been disguised.

There are some additional methodological issues in our study that need to be addressed. It has been claimed that the binding of bacteria to exfoliated cells, as performed in our assay, is an in vitro artifact of no clinical importance [25]. However, at present there are no other methods that enable studies of the influence of bronchial diseases on bacterial adhesion. Furthermore, our finding of different adhesion properties for cells from different subject groups shows that the assay is influenced by events occurring before exfoliation, e.g. disease processes, such as chronic bronchitis, and thus have a clinical implication. We cannot rule out the possibility that our bacterial test strains could bind to mucus as well as to exfoliated cells, especially since we focused on subjects with chronic bronchitis known to have a production of excess mucus and bacterial infections. Earlier studies using organ culture of respiratory mucosa have shown a binding of $S$. pneumoniae [24] and $H$. influenzae [26] to mucus. However, we did not observe any mucus strands associated with the exfoliated cells, or bacteria adhering to mucus, and we believe that most mucus had been washed away during the adhesion assay.

In summary, adhesion of $H$. influenzae to ciliated columnar cells and goblet cells from the bronchi was demonstrated, and increased adherence was found to bronchial cells, especially goblet cells, from patients with nonobstructive chronic bronchitis. Bacterial adhesion to airway epithelial cells may be a factor of importance 
for colonization and retention of $H$. influenzae intrabronchially. The role of adhesion for colonization with $S$. pneumoniae intrabronchially seems, however, to be less clear. We found no evidence that increased bacterial adhesion can explain why some patients with chronic bronchitis develop recurrent infectious exacerbations.

\section{References}

1. Reynolds HY. Bacterial adherence to respiratory tract mucosa: a dynamic interaction leading to colonization. Semin Respir Infect 1987; 2: 8-19.

2. Beachey EH, Giampapa CS, Abraham SN. Bacterial adherence: adhesin receptor-mediated attachment of pathogenic bacteria to mucosal surfaces. Am Rev Respir Dis 1988; 138: S45-S48.

3. Plotkowski MC, Bajolet-Laudinat O, Puchelle E. Cellular and molecular mechanisms of bacterial adhesion to respiratory mucosa. Eur Respir J 1993; 6: 903916.

4. Toumanen E, Towbin H, Rosenfelder G, et al. Receptor analogs and monoclonal antibodies that inhibit adherence of Bordetella pertussis to human ciliated respiratory epithelial cells. J Exp Med 1988; 168: 267277.

5. Niederman MS, Rafferty TD, Sasaki CT, Merrill WW, Matthay RA, Reynolds HY. Comparison of bacterial adherence to ciliated and squamous epithelial cells from the human respiratory tract. Am Rev Respir Dis 1983; 127: 85-90.

6. Schwab UE, Wold AE, Carson JL, et al. Increased adherence of Staphylococcus aureus from cystic fibrosis lungs to airway epithelial cells. Am Rev Respir Dis 1993; 148: 365-369.

7. Raman AS, Swinburne AJ, Fedullo AJ. Pneumococcal adherence to the buccal epithelial cells of cigarette smokers. Chest 1983; 83: 23-27.

8. Mahajan B, Panhotra BR. Adherence of Streptococcus pneumoniae to buccal epithelial cells of smokers and nonsmokers. Indian J Med Res 1989; 89: 381-383.

9. Fainstein V, Musher D. Bacterial adherence to pharyngeal cells in smokers, nonsmokers, and chronic bronchitics. Infect Immun 1979; 26: 178-182.

10. Fletcher CM, Pride NB. Definitions of emphysema, chronic bronchitis, asthma, and airflow obstruction: 25 years on from the CIBA symposium. Thorax 1984; 39: $81-85$.

11. Bates JH. The role of infection during exacerbations of chronic bronchitis. Ann Intern Med 1982; 97: 130-131.

12. Riise GC, Larsson S, Larsson P, Jeansson S, Andersson BA. The intrabronchial microbial flora in chronic bronchitis patients. A target for $\mathrm{N}$-acetylcysteine therapy? Eur Respir J 1994; 7: 94-101.

13. Irwin RS, Erickson AD, Pratter MR, et al. Prediction of tracheobronchial colonization in current cigarette smokers with chronic obstructive bronchitis. $J$ Infect Dis 1982; 145: 234-241.

14. Fagon J-Y, Chastre J, Troillet J-L, et al. Characterization of distal bronchial microflora during acute exacerbation of chronic bronchitis. Am Rev Respir Dis 1990; 142: 1004-1008.

15. Tager I, Speizer FE. Role of infection in chronic bronchitis. N Engl J Med 1975; 292: 563-571.

16. Haas H, Morris JF, Samson S, Kilbourn JP, Kim PJ. Bacterial flora of the respiratory tract in chronic bronchitis: comparison of transtracheal, fiberbronchoscopic and oropharyngeal sampling methods. Am Rev Respir Dis 1977; 116: 41-47.

17. Boman G, Bäcker U, Larsson S, Melander B, Wählander L. Oral acetylcysteine reduces exacerbation rate in chronic bronchitis: report of a trial organized by the Swedish Society for Pulmonary Diseases. Eur J Respir Dis 1983, 64: 405-415.

18. Andersson B, Eriksson B, Falsen E, et al. Adhesion of Streptococcus pneumoniae to human pharyngeal epithelial cells in vitro: Differences in adhesive capacity among strains isolated from subjects with otitis media, septicemia, or meningitis, or from healthy carriers. Infect Immun 1981; 32: 311-317.

19. Porras O, Svanborg-Eden C, Lagergård T, Hanson LÅ. Method for testing adherence of Haemophilus influenzae to human buccal epithelial cells. Eur J Clin Microbiol 1985; 4: 310-315.

20. Spurzem JR, Thompson AB, Daughton DM, Mueller M, Linder J, Rennard SI. Chronic inflammation is associated with an increased proportion of goblet cells recovered by bronchial lavage. Chest 1991; 100: 389-393.

21. Groeneveld K, Eijk P, van Alphen L, Jansen H, Zanen $\mathrm{H}$. Haemophilus influenzae infections in patients with chronic obstructive pulmonary disease despite specific antibodies in serum and sputum. Am Rev Respir Dis 1990; 141: 1316-1321.

22. Andersson BA, Gray BM, Dillon Jr HC, Bahrmand A, Svanborg-Eden C. Role of adherence of Streptococcus pneumoniae in acute otitis. Pediatr lnfect Dis 1988; 7: 476-480.

23. Selinger DS, Reed WP. Pneumococcal adherence to human epithelial cells. Infect Immun 1979; 23: 545548.

24. Plotkowski M-C, Beck G, Jacquot J, Puchelle E. The frog palate mucosa as a model for studying bacterial adhesion to mucus-coated respiratory epithelium. J Comp Pathol 1989; 100: 37-46.

25. Feldman C, Read R, Rutman R, et al. The interaction of Streptococcus pneumoniae with intact human respiratory mucosa in vitro. Eur Respir J 1992; 5: 576-583.

26. Read RC, Wilson R, Rutman A, et al. Interaction of nontypable Haemophilus influenzae with human respiratory mucosa in vitro. J Infect Dis 1991; 163: 549-558. 